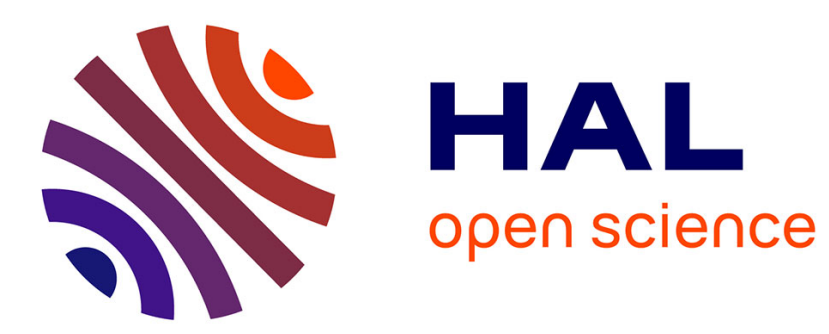

\title{
Quantum Coherence in Semiconductor Microlasers
}

Djeylan Aktas, Tao Wang, Olivier Alibart, Gian-Luca Lippi, Eric Picholle, Sébastien Tanzilli

\section{To cite this version:}

Djeylan Aktas, Tao Wang, Olivier Alibart, Gian-Luca Lippi, Eric Picholle, et al.. Quantum Coherence in Semiconductor Microlasers. CLEO 2016 - Conference on Lasers and Electrooptics, Optical Society of América, Jun 2016, San Jose, United States. 10.1364/CLEO_SI.2016.SF2L.6 . hal-01352529

\section{HAL Id: hal-01352529 \\ https://hal.science/hal-01352529}

Submitted on 8 Aug 2016

HAL is a multi-disciplinary open access archive for the deposit and dissemination of scientific research documents, whether they are published or not. The documents may come from teaching and research institutions in France or abroad, or from public or private research centers.
L'archive ouverte pluridisciplinaire HAL, est destinée au dépôt et à la diffusion de documents scientifiques de niveau recherche, publiés ou non, émanant des établissements d'enseignement et de recherche français ou étrangers, des laboratoires publics ou privés. 


\title{
Quantum Coherence in Semiconductor Microlasers
}

\author{
Djeylan Aktas, ${ }^{1}$ Tao Wang, ${ }^{2}$ Olivier Alibart, ${ }^{1}$ Gian Luca Lippi, ${ }^{2}$ Éric Picholle, ${ }^{1}$ and Sébastien Tanzilli ${ }^{1}$ \\ 1. Laboratoire de Physique de la Matière Condensée, CNRS UMR 7336, Université de Nice Sophia Antipolis, \\ Parc Valrose, 06100 Nice cedex, France \\ 2. Institut Non Linéaire de Nice, CNRS UMR 7335, Université de Nice Sophia Antipolis, \\ 1361 route des Lucioles, Sophia Antipolis, 06560 Valbonne, France \\ eric.picholle@unice.fr, gian-luca.lippi@inln.cnrs.fr
}

\begin{abstract}
The buildup of the coherence of a Class-B semiconductor microlaser in the subthreshold region is characterized by photon coincidence. Correlation values $g^{(2)}(0)>2$ confirm the key role of spatio-temporal dynamics in the photon statistics.
\end{abstract}

OCIS codes: 250.5960 Semiconductor lasers ; 270.5290 Photon statistics ; 140.3430 Laser theory

\section{Introduction}

Lasers are often perceived as threshold devices, with a rapid all-or-nothing transition around threshold. This approach usually holds for high quality factor ("Class A" [1]) devices or macroscopic ones, but fails to correctly describe the transition in very small samples. The long carrier lifetime - compared to the cavity time - typical of semiconductor-based micro- and nanolasers ("Class B" devices) introduces an additional element of complexity to the problem due to the nontrivial dynamical evolution [2,3] of the coherent fraction of electromagnetic field, and opens questions on coherence buildup.

Below threshold, the characterization of the latter is rendered difficult due to the small number of photons contained in the laser cavity at any given time, thus yielding very low optical intensity levels, close to or below the sensitivity limit of standard photodetectors. Fortunately, recent telecom-based quantum measurement techniques [4] now allow the assessment of the laser's degree of coherence through its second order correlation function, $\mathrm{g}^{(2)}(\tau)$.

\section{Experimental setup}

We elected to characterize a commercial Class B laser, Thorlabs VCSEL-980 $(\lambda=980 \mathrm{~nm})$. The attenuated beam reaches, through a standard 50/50 fiber coupler, two independent IdQuantique ID100 photon detectors. Detection events are correlated through a Ortec 567 time-to-amplitude converter (TAC). Coincidence events are accounted for and mapped. (Fig. 1) The jitter of the detectors is estimated at $40 \mathrm{ps}$, and the resolution of the TAC at $15 \mathrm{ps}$.

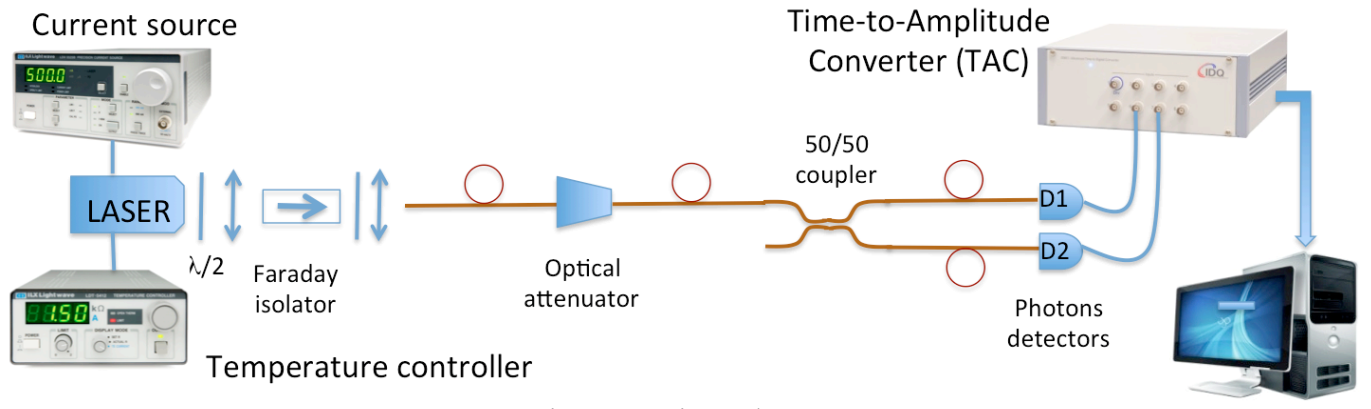

Fig. 1. Experimental setup

\section{Results}

This approach allows us to study the transition region at low pump values and to characterize the coherence buildup from a mostly incoherent regime well below threshold (Fig. 2a) towards the usual multimode regime above threshold, passing through different statistical mixtures of coherent and incoherent components. The growth of a signal at the center of the histograms, on top of the detector background, indicates the growth of short-term coherence. Its progressive enlargement with increasing pump currents concurs both with classical-based measurements above threshold [2] and with numerical simulations of the transition region performed by taking into account intrinsic fluctuations at threshold [3]. 
The associated second order correlation function, $\mathrm{g}^{(2)}(\tau)$, also allows a characterization of the degree of coherence of the laser. Further increase in pump produces a flattening of the correlation (not shown), corresponding to the establishment of long-range temporal coherence shown in Fig. $3\left(\mathrm{~g}^{(2)}(0)=1\right.$, right portion of the curve), in agreement with $[2,3]$.
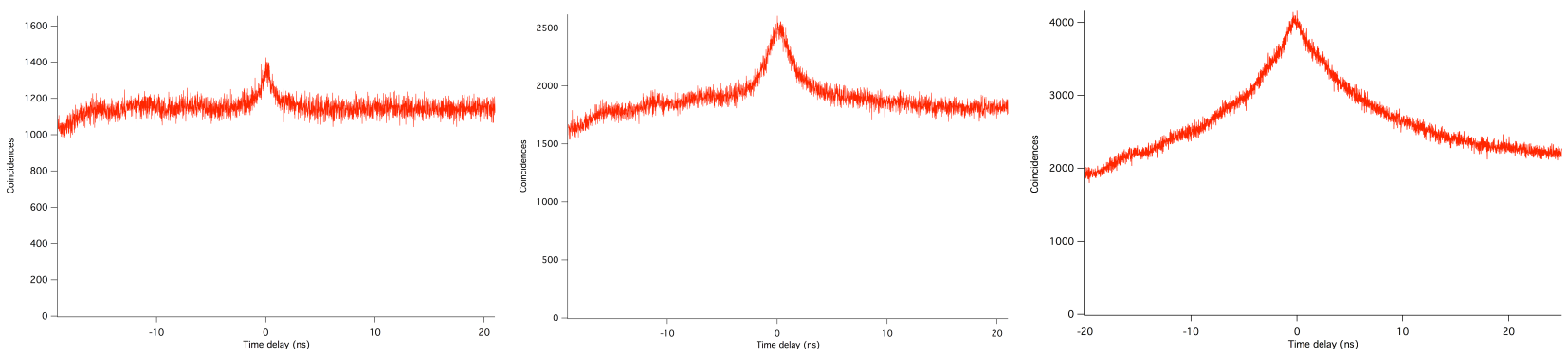

Fig. 2. Progressive buildup of the laser coherence: Histograms of coincidence events $(\Delta t=0:$ time-bin 78$)$. From left to right, pumping intensities are (a) $I_{p}=1.15 \mathrm{~mA}$; (b) $I_{p}=1.20 \mathrm{~mA} \&$ (c) $I_{p}=1.30 \mathrm{~mA}$.

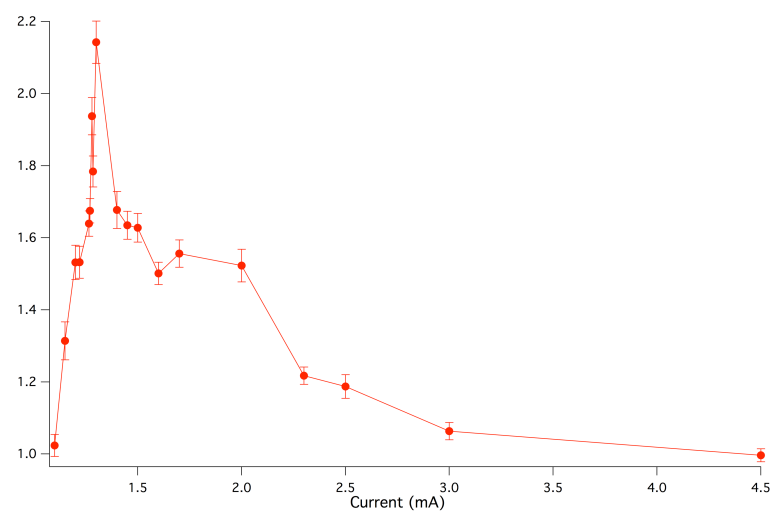

Fig. 3. Experimental correlation function $\mathrm{g}^{(2)}(0)$

We also observe, for the first time in this context, correlation values $\mathrm{g}^{(2)}(0)$ up to $2.14 \pm 0.06$ at $\mathrm{I}_{\mathrm{p}}=1.30 \mathrm{~mA}$ (Fig. 3). Such values, significantly higher than the theoretical values for chaotic light $\left(g^{(2)}(0)=2\right)$, can easily be interpreted by taking into account the temporal dynamics of the source in the extended threshold region, where bursts of shorts pulses can be classically observed [2], in good agreement with our stochastic model [3], instead of the traditionally expected $\mathrm{cw}$ behaviour above threshold: the concentration of detection events during a pulse increases the probability of coincidence events, thus $\mathrm{g}^{(2)}(0)$. The apparent decrease in correlation for very low values of the pump current (left side of Fig. 3 ) is an artefact stemming from the limited temporal resolution of the TAC.

\section{Conclusion}

Quantum measurement techniques based on telecom technology appear as a promising tool for the characterization of the coherence of micro- and nano-lasers at low pump levels, where classical measurements become difficult. Further developments, and the implementation of a better temporal resolution both for the photon detectors and the TDC, should also allow an indirect characterization of the temporal dynamics of these lasers. In addition, these experimental measurements validate the theoretical approach of the stochastic simulator [3].

\section{References}

[1] F.T. Arecchi, G.L. Lippi, G.P. Puccioni, and J. R. Tredicce, "Deterministic chaos in laser with injected signal", Optics Comm., 51, 308-314 (1984).

[2] T. Wang, G.P. Puccioni, and G.L. Lippi, “Dynamical Buildup of Lasing in Mesoscale Devices”, Sci. Rep. 5, 15858 (2015).

[3] G.P. Puccioni, and G.L. Lippi, "Stochastic simulator for modeling the transition to lasing", Opt. Express, 23, 2369 (2015).

[4] L.A. Ngah, O. Alibart, L. Labonté, V. D'Auria, and S. Tanzilli, "Ultra-fast heralded single photon source based on telecom technology", Laser \& Photon. Rev. 9, L1-L5 (2015). 